\title{
Distribution and relative activity of matrix metalloproteinase-2 in human coronal dentin
}

\author{
Lee W. Boushell ${ }^{1}$, Masaru Kaku${ }^{2}$, Yoshiyuki Mochida ${ }^{3}$, Mitsuo Yamauchi $^{4}$ \\ ${ }^{I}$ Department of Operative Dentistry, School of Dentistry, University of North Carolina, Chapel Hill NC 27599, USA; \\ ${ }^{2}$ Department of Bio-Prosthodontics, Medical and Dental Science, Niigata University Graduate School Chuo-ku, \\ Niigata City 951-8514, Japan; ${ }^{3}$ Department of Periodontology and Oral Biology, Division of Oral Biology, Boston \\ University, Henry M. Goldman School of Dental Medicine, Center for Advanced Biomedical Research, Boston \\ MA 02118, USA; ${ }^{4}$ Dental Research Center, School of Dentistry, University of North Carolina, Chapel Hill NC 27599, \\ USA
}

The presence of matrix metalloproteinase-2 (MMP-2) in dentin has been reported, but its distribution and activity level in mature human coronal dentin are not well understood. The purpose of this study was to determine the MMP-2 distribution and relative activity in demineralized dentin. Crowns of twenty eight human molars were sectioned into inner (ID), middle (MD), and outer dentin (OD) regions and demineralized. MMP-2 was extracted with $0.33 \mathrm{~mol} \cdot \mathrm{L}^{-1}$ EDTA/2 $\mathrm{mol} \cdot \mathrm{L}^{-1}$ guanidine-HCl, $\mathrm{pH} 7.4$, and MMP-2 concentration was estimated with enzyme-linked immunoabsorbant assay (ELISA). Further characterization was accomplished by Western blotting analysis and gelatin zymography. The mean concentrations of MMP-2 per mg dentin protein in the dentin regions were significantly different $(P=0.043)$ : $0.9 \mathrm{ng}$ (ID), $0.4 \mathrm{ng}$ (MD), and $2.2 \mathrm{ng}$ (OD), respectively. The pattern of MMP-2 concentration was $\mathrm{OD}>\mathrm{ID}>\mathrm{MD}$. Western blotting analysis detected $\sim 66$ and $\sim 72 \mathrm{kDa}$ immunopositive proteins corresponding to pro- and mature MMP-2, respectively, in the ID and MD, and a $\sim 66 \mathrm{kDa}$ protein in the OD. Gelatinolytic activity consistent with MMP-2 was detected in all regions. Interestingly, the pattern of levels of Western blot immunodetection and gelatinolytic activity was MD $>$ ID $>0 D$. The concentration of MMP-2 in human coronal dentin was highest in the region of dentin that contains the dentinoenamel junction and least in the middle region of dentin. However, levels of Western blot immunodetection and gelatinolytic activity did not correlate with the estimated regional concentrations of MMP-2, potentially indicating region specific protein interactions.

Keywords: matrix metalloproteinase-2; human coronal dentin; distribution; gelatinolytic activity

International Journal of Oral Science (2011) 3: 192-199. doi: 10.4248/IJOS11070

\section{Introduction}

Fibrillar type I collagen is the predominant matrix component in dentin providing the structural framework of dentin accommodating the hydroxyapatite crystals

*Correspondence: Lee W. Boushell

Tel: 001919966 2776; Fax: 0019199665660

E-mail: Boushell@dentistry.unc.edu

Received 2 June 2010; Accepted 23 August 2011 within and around the fibrils. The specific association and organization of these two phases are likely critical in the structure and in maintaining the mechanical properties of this tissue [1].

Various matrix metalloproteinases (MMPs) have been reported as present in dentin, possibly regulating the collagen fibril organization and mineralization [2-7]. Tissue inhibitors of metalloproteinases (TIMPs) in dentin could play an MMP inhibitory role during dentinogenesis $[5,8]$. Several studies have also suggested that 
the endogenous MMPs, such as a collagenase (MMP-8) and the gelatinases (MMP-2 and -9), have a critical role in caries progression and disruption of the hybrid layer formed during dentin bonding [9-18].

Our previous study utilizing immunohistochemical (IHC) methodologies suggested that MMP-2 in human coronal dentin is concentrated close to the predentin and near the dentinoenamel junction (DEJ) [6]. However, this approach confirms neither the quantity nor the activity of the protease. Therefore, the purpose of this study was to utilize enzyme-linked immunoabsorbant assay (ELISA), Western blotting, and gelatin zymography to further characterize the concentration, form (i.e. pro- vs. mature), and gelatinolytic activity of MMP-2 in the inner (ID), middle (MD), and outer (OD) regions of human coronal dentin.

\section{Material and Methods}

\section{Coronal dentin specimen preparation}

Twenty eight human third molars (19 female, 9 male) were obtained immediately after extraction and disinfected in a $1 \%$ Thymol solution for $5 \mathrm{~d}$ at $4{ }^{\circ} \mathrm{C}$. The roots from each molar were removed and the coronal tooth structure was sectioned into ID, MD, and OD regions with a low speed saw (Isomet ${ }^{\mathrm{TM}} 1000$ Precision Saw, Bueler Corporation, Lake Bluff, USA) at $100 \mathrm{r} \cdot \mathrm{min}^{-1}$ with $\sim 2{ }^{\circ} \mathrm{C}$ water cooling (Figure 1). All pulp tissue and predentin was carefully removed from each of the ID sections. The majority of the enamel was removed from each section of OD. All sections were rinsed with distilled deionized water (DDW). The ID, MD, and OD sections from multiple crowns were combined to obtain

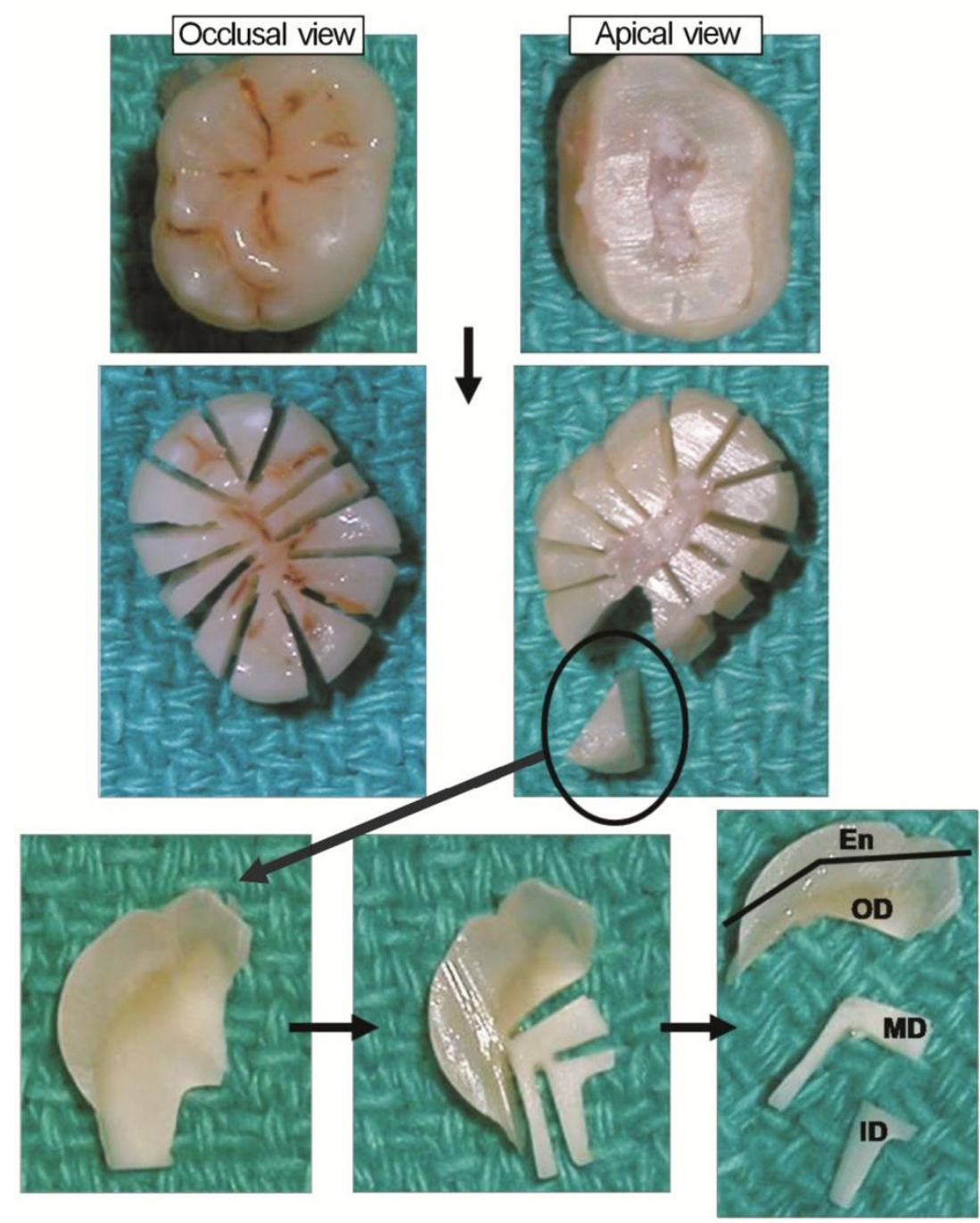

Figure 1 Radial sectioning technique for dividing the tooth into inner (ID), middle (MD), outer (OD) dentin and enamel (En). Arrows indicate flow of sectioning procedures. 
an adequate amount of regional dentin for protein extraction procedures.

The specimens of each region were pulverized under liquid $\mathrm{N}_{2}$ in Spex Freezer/Mill 6770 (Spex SamplePrep, Metuchen, USA), washed with cold DDW, and lyophilized. The dried samples were then extracted two times for $48 \mathrm{~h}$ at $4{ }^{\circ} \mathrm{C}$ each with $10 \mathrm{~mL}$ of extraction buffer $\left(0.33 \mathrm{~mol} \cdot \mathrm{L}^{-1}\right.$ ethylenediaminetetraacetic acid (EDTA) and
$2 \mathrm{~mol} \cdot \mathrm{L}^{-1}$ guanidine $\mathrm{HCl}(\mathrm{pH} 7.4)$ ) for every gram of sample. The combined supernatents and insoluble residues were exhaustively dialyzed against DDW, lyophilized, weighed, and stored at $-80{ }^{\circ} \mathrm{C}$ until use. Pre- and postdemineralization/extraction dry weights and percent organic phase by weight of the ID, MD, and OD regions were calculated to ascertain level of demineralization (Table 1).

Table 1 ID, MD, OD region protein extract weights and percent organic phase by weight

\begin{tabular}{ccccc}
\hline Region & $\begin{array}{c}\text { Mineralized } \\
\text { dry weight/g }\end{array}$ & $\begin{array}{c}\mathrm{E}+\mathrm{G} \text { extract } \\
\text { dry weight/mg }\end{array}$ & $\begin{array}{c}\text { Insoluble residue } \\
\text { dry weight/mg }\end{array}$ & $\begin{array}{c}\text { Amount of organic } \\
\text { dentin phase } / \%\end{array}$ \\
\hline ID & 0.996 & 59 & 114 & 17.4 \\
MD & 2.020 & 72 & 328 & 20.0 \\
OD* & 16.070 & 681 & 1066 & 10.9 \\
\hline
\end{tabular}

ID: inner dentin; MD: middle dentin; OD: outer dentin; E: EDTA; G: guanidine $\mathrm{HCl}$.

*: includes some enamel.

A 1 or $2 \mathrm{mg}$ sample of each extract was dissolved in sodium dodecyl sulfate (SDS) sample buffer $\left(100 \mathrm{mmol} \cdot \mathrm{L}^{-1}\right.$ tris-HCl, $\mathrm{pH} 8.8,0.01 \%$ bromophenol blue, 36\% glycerol, $4 \%$ SDS) and incubated at $60{ }^{\circ} \mathrm{C}$ for $1 \mathrm{~h}$. Experiments revealed that $\sim 61 \mathrm{kDa}$ active, rhMMP-2 (Calbiochem, EMD Biosciences Inc., San Diego, USA) retained its gelatinolytic activity under this condition up to 4 hours. The rhMMP-2 was used as a positive control. Protein concentration was measured by DC protein assay kit $\left(\mathrm{DC}^{\mathrm{TM}}\right.$ protein assay, Bio-Rad Laboratories Inc., Hercules, USA).

\section{MMP-2 concentration determination}

The concentration of MMP-2 in each region was estimated by ELISA. A standard curve using absorbance at dual wavelengths $(450 / 595 \mathrm{~nm})$ of known concentrations of MMP-2 was developed. The absorbance of samples with unknown amounts of MMP-2 was compared with standards to calculate the approximate MMP-2 concentration (ng MMP-2/mg of dentin protein). (Calbiochem MMP-2 ELISA Kit QIA63, EMD Biosciences, San Diego, USA). The manufacturer reported that this assay detects the pro- and mature MMP-2 forms as well as the MMP-2/TIMP-2 complex. Dentin extracts were run in duplicate in each of 3 assays. Results of pilot experiments measuring rhMMP-2 concentration were the same as controls when using assay buffer with less than or equal to $0.125 \%$ SDS. Therefore, all dentin samples were diluted to limit the maximum concentration of SDS to $0.125 \%$.
Western blotting analysis

$25 \mu \mathrm{g}$ of dentin and enamel extracts were dissolved in SDS sample buffer with $10 \mathrm{mmol} \cdot \mathrm{L}^{-1}$ dithiothreitol (DTT) and applied to 4\%-12\% SDS-polyacrylamide gel electrophoresis (PAGE), transferred to a polyvinylidene fluoride (PVDF) membrane, subjected to Western blotting analysis $(n=3)$ with anti MMP-2 monoclonal antibody (anti-MIMP-2 (Ab-3), Calbiochem, EMD Biosciences Inc., San Diego, USA) and a second anti MMP-2 monoclonal antibody (anti-MMP-2/8B4 (Ab7032), Abcam Inc., Cambridge, USA). The immunoreactivity was visualized using an alkaline phosphatase substrate kit (Bio-Rad Laboratories Inc., Hercules, USA).

\section{Gelatin zymography}

Analysis of gelatinolytic activity in the dentin extracts was performed under non-denaturing conditions using gelatin zymography. Experiments revealed that $120 \mu \mathrm{g}$ of dentin protein extracts allowed detection of gelatinolytic activity. Extracts were electrophoresed on $10 \%$ gelatin zymogram gels (Invitrogen Corporation, Carlsbad, USA). Ten nanograms of rhMMP-2 were used as a positive control. The zymograms $(n=3)$ were developed at $37{ }^{\circ} \mathrm{C}$ for $48 \mathrm{~h}$ with constant oscillation in a humid environment. The zymograms were then stained with SimplyBlue ${ }^{\mathrm{TM}}$ SafeStain (Invitrogen Corporation, Carlsbad, USA) overnight and washed with DDW for $1 \mathrm{~h}$.

\section{Statistical analysis}

The concentrations for the three regions from the three 
ELISA experiments were analyzed using an exact analysis of variance test with general scores, a permutation test (StatXact8, Cytel Zncorporated, Cambridge, USA).

This research was approved by the UNC Biomedical Institutional Review Board.

\section{Results}

ELISA $(n=3)$ specific for MMP-2 indicated that the mean concentration of MMP-2 was highest in the OD (2.2 ng MMP-2/mg $\pm 1.0 \mathrm{ng}$ MMP-2/mg), followed by ID (0.9 ng MMP-2/mg $\pm 0.3 \mathrm{ng} \mathrm{MMP}-2 / \mathrm{mg})$ and $\mathrm{MD}$ (0.4 ng MMP-2/mg $\pm 0.2 \mathrm{ng}$ MMP-2/mg) (Table 2). The difference in the mean concentrations of MMP-2 in ID, $\mathrm{MD}$ and OD was statistically significant $(P=0.043)$ indicating there are regional differences in MMP-2 concentration. The pattern of mean concentration ( $\mathrm{OD}>\mathrm{ID}>\mathrm{MD})$ was consistent for all three ELISA experiments (Table 2).

Table 2 MMP-2 concentration in ID, MD and OD based on ELISA

\begin{tabular}{cccc}
\hline $\begin{array}{c}\text { ELISA experiment } \\
\#\end{array}$ & $\begin{array}{c}\text { ID } \\
\text { (ng MMP-2/mg ID) }\end{array}$ & $\begin{array}{c}\text { MD } \\
\text { (ng MMP-2/mg MD) }\end{array}$ & $\begin{array}{c}\text { OD } \\
\text { (ng MMP-2/mg OD) }\end{array}$ \\
\hline 1 & 0.6 & 0.3 & 1.1 \\
2 & 1.2 & 0.6 & 3.0 \\
3 & 0.8 & 0.3 & 2.4 \\
Mean \pm SD* & $0.9 \pm 0.3$ & $0.4 \pm 0.2$ & $2.2 \pm 1.0$ \\
\hline
\end{tabular}

ID: inner dentin; MD: middle dentin; OD: outer dentin (includes some enamel).

*: the average concentration among the three regions was statistically significantly different $(P=0.043)$.

Western blotting analyses $(n=3)$ for MMP-2 indicated the presence of a distinct band at $\sim 66 \mathrm{kDa}$ range in the ID, MD and OD extracts corresponding to the molecular weight of the active form of MMP-2 (Figure 2). The ID and MD extracts also demonstrated a faint band that migrated slightly higher ( $\sim 2 \mathrm{kDa})$, likely representing pro-MMP-2. Immunopositive bands at two high molecular weight proteins (between $150 \mathrm{kDa}$ and $115 \mathrm{kDa}$ ) in the ID and MD extract were also present (Figure 2). Both monoclonal antibodies (Ab3 and Ab7072) reacted with purified rhMMP-2 $(\sim 61 \mathrm{kDa})$ and demonstrated an immunopositive band at $\sim 66 \mathrm{kDa}$ protein in the dentin extracts (Figures 2, 3). Active and pro-forms of MMP-2 were most readily detected in MD, followed by ID and OD. Higher molecular weight immunopositive bands suggestive of MMP-2 complex formation were present in ID and MD.

Gelatin zymography $(n=3)$ revealed ID, MD, and OD gelatinolytic activity at a slightly higher migration position than the rhMMP-2 control corresponding to the active form of MMP-2 (Figure 4). Faint gelatinolytic activity corresponding to the proform of MMP-2 was detected in the ID and MD extracts. Faint gelatinolytic activity at $\sim 38 \mathrm{kDa}$ was also detected in the ID and MD extracts likely representing the MMP-2 catalytic domain. The presence of gelatinolytic activity at $\sim 34 \mathrm{kDa}$ in the MD indicates additional autolytic breakdown products. The gelatinolytic activity of MMP-2 was most readily detected in the MD, followed by ID and OD.

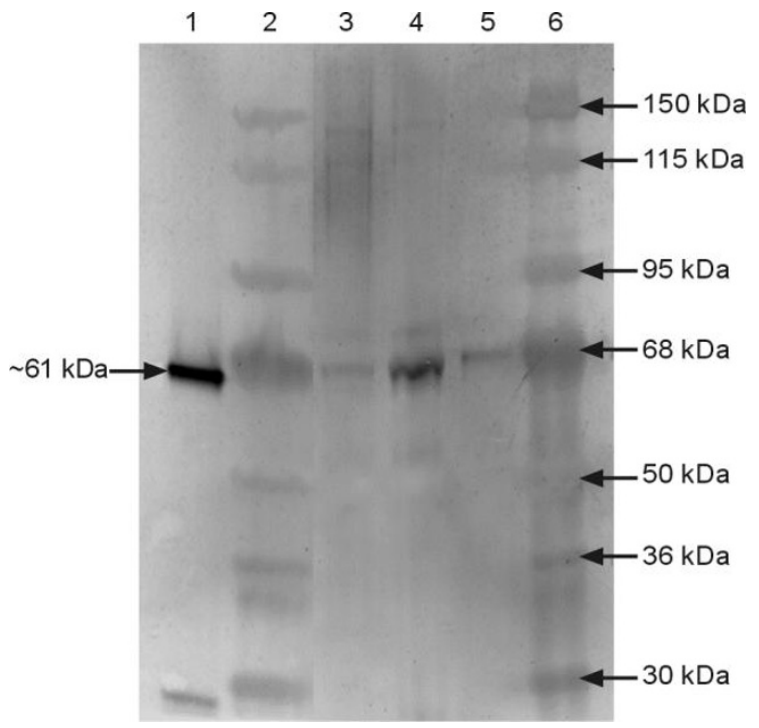

Figure 2 Western blotting analysis with anti-MMP-2 (Ab3). Lane 1: rhMMP-2 positive control; lane 2: molecular weight (MW) standards; lane 3: ID extract with immunopositive bands at $\sim 72 \mathrm{kDa}$ and $\sim 66 \mathrm{kDa}$ and between $150 \mathrm{kDa}$ and $115 \mathrm{kDa}$; lane 4: MD extract with immunopositive bands at $\sim 72 \mathrm{kDa}$ and $\sim 66 \mathrm{kDa}$ and between $150 \mathrm{kDa}$ and $115 \mathrm{kDa}$; lane 5: OD extract with immunopositive $\sim 66 \mathrm{kDa}$ band; lane 6 : MW standards. 


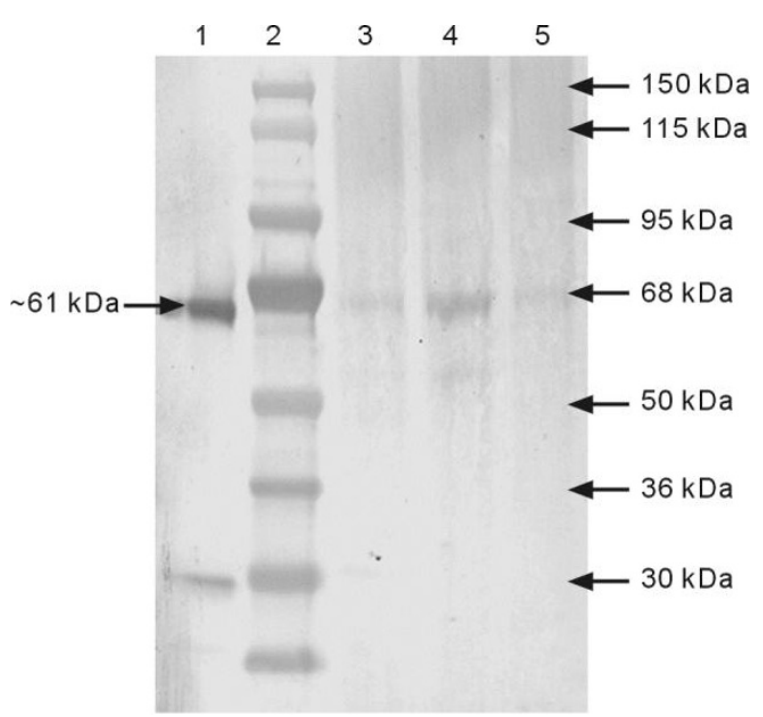

Figure 3 Western blotting analysis of dentin extracts with anti-MMP-2 (Ab7032). Lane 1: rhMMP-2 control ( 61 kDa MMP-2 and autolytic degradation products); lane 2: MW standards; lane 3: ID extract with immunopositive $\sim 66 \mathrm{kDa}$ band; lane 4: MD extract with immunopositive $\sim 66 \mathrm{kDa}$ band; lane 5: OD extract with immunopositive $\sim 66 \mathrm{kDa}$ band.

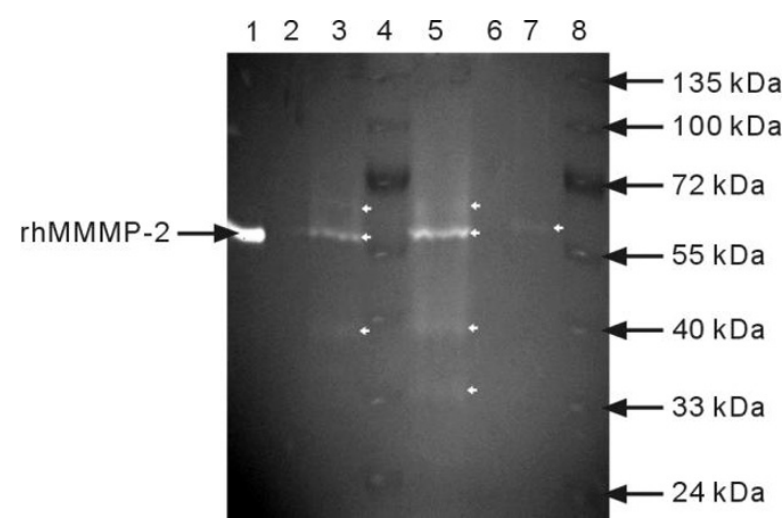

Figure 4 Gelatin zymogram of ID, MD and OD dentin extracts. Lane 1: rhMMP-2 control ( $61 \mathrm{kDa})$; lane 2: blank lane; lane 3 : ID extract revealing gelatinolytic activity at $\sim 66 \mathrm{kDa}$, faint higher MW MMP-2 zymogen and autolytic breakdown product at $\sim 38 \mathrm{kDa}$; lane 4 : MW standards; lane 5: MD extract revealing gelatinolytic activity at $\sim 66 \mathrm{kDa}$, faint higher MW MMP-2 zymogen and autolytic breakdown product at $\sim 38$ and $\sim 34 \mathrm{kDa}$; lane 6: blank lane; lane 7: OD extract revealing faint gelatinolytic activity at $\sim 66 \mathrm{kDa}$; lane 8 : MW standards. MW standard bands were mechanically punctured before staining (small white areas within MW marker bands) for ease of identification.

\section{Discussion}

Previous immunohistochemical analyses of human coronal dentin revealed intense MMP-2 immunoreactivity in two areas, i.e. the inner $200 \mu \mathrm{m}$ of the dentin (near predentin) and the outer $\sim 10 \mu \mathrm{m}$ (adjacent to the DEJ) [6]. Therefore, this study utilized a novel method of tooth sectioning to allow for separation of these regions from the middle dentin region, where IHC for MMP-2 suggested a lower concentration. ELISA was used to obtain more insight into relative regional MMP-2 concentrations. Western blotting was used to further characterize MMP-2/MMP-2 complexes. Gelatin zymography was used to compare levels of regional MMP-2 enzymatic activity.

ELISA and Western blotting assays, similar to IHC, depend on antibody specificity and epitope availability. ELISA allows detection of MMP-2 suspended in fluid phase. Western blotting involves the electrophoretic separation of various proteins by size followed by immobilization of MMP-2 on a PVDF or nitrocellulose membrane before immunodetection is attempted. These assay differences may lead to variation in epitope recognition and results should be compared and interpreted with caution. Gelatin zymography is able to reveal MMP-2 activity, but regional levels of activity may not correlate directly with the concentration of MMP-2 actually present secondary to the presence and influence of other noncollagenous proteins.

It has been noted in human adult teeth that in vitro acidic $\mathrm{pH}$ induced loss of tooth structure continues to occur even after return to physiologic $\mathrm{pH}$ in the presence of a collagenase [9, 19-20]. Therefore a combined EDTA and guanidine- $\mathrm{HCl}$ extraction buffer was used to simultaneously extract dentinal tubule content, mineral associated proteins, and matrix proteins at physiologic $\mathrm{pH}$ under conditions that inhibit MMP proteolytic activity [21-22]. EDTA inhibits MMP proteolytic activity by removal of the zinc cation necessary for activity and calcium cations necessary for tertiary structure. Western blotting and gelatin zymography pilot studies of human coronal dentin, that had soluble proteins extracted by a $4 \mathrm{~mol} \cdot \mathrm{L}^{-1}$ guanidine $-\mathrm{HCl} / 0.5 \mathrm{~mol} \cdot \mathrm{L}^{-1} \mathrm{EDTA} / 4 \mathrm{~mol} \cdot \mathrm{L}^{-1}$ guandine- $\mathrm{HCl}$ extraction series, revealed very similar levels of MMP-2 detection and activity when compared with the combined $2 \mathrm{~mol} \cdot \mathrm{L}^{-1}$ guanidine- $\mathrm{HCl} / 0.33 \mathrm{~mol} \cdot \mathrm{L}^{-1}$ EDTA extraction results of this study. Furthermore, as seen in Table 1, calculation of the weight of dentin matrix organic phase indicated appropriate matrix demineralization under the conditions utilized in this study. Extraction of the soluble dentin proteins revealed a range of concentrations of MMP-2 in the ID, MD and 
OD extracts ( 0.4 to $2.2 \mathrm{ng}$ MMP-2/mg dentin matrix protein) consistent with other research that used ELISA for MMP-2 concentration determination [12]. Previous IHC studies of embryonic mouse and rat tooth germs as well as demineralized adult human coronal dentin found regional MMP-2 concentration differences, specifically that MMP-2 was concentrated in the predentin, the inner dentin area adjacent to the predentin as well as adjacent to the DEJ [2, 5-6]. The increased level of MMP-2 immunoreactivity in ID, observed by light microscopy, was primarily due to the presence of MMP-2 in association with the odontoblastic processes in human coronal dentin. Although MMP-2 was detected throughout human coronal dentin, IHC also revealed an increased level of immunostaining of MMP-2 in association with the matrix at the DEJ [6]. The ELISA used here reveals the same pattern of MMP-2 concentration differences that is consistent with IHC studies [5-6].

Characterization using Western blotting for MMP-2 revealed that the $\sim 66 \mathrm{kDa}$ active and $\sim 72 \mathrm{kDa}$ pro-form was more readily detected in the middle as compared with inner and outer dentin extracts. Slight variations in gel electrophoresis migration positions of MMP-2 in the different extracts may represent varied extent of post translational modifications such as glycosylation. It was expected that the regional levels of MMP-2 immunodetection by Western blotting would follow a pattern similar to that revealed by ELISA: however, the opposite was found. Immunodetection of two high molecular weight protein bands ( $\sim 140$ and $\sim 120 \mathrm{kDa}$, respectively) was greater in the ID than the MD extract and was absent in the OD (Figure 2). These bands may indicate MMP-2 complex formation with other proteins such as a TIMP, proteoglycan or bone sialoprotein (BSP) that could not be dissociated under the conditions used [23-26]. A greater amount of high molecular weight MMP-2 complex formation in the ID may explain the lower level of immunodetection of the pro-MMP-2 and MMP-2 as compared with MD. The inclusion of some enamel protein in the OD may have resulted in MMP-2/ protein interactions that effect immunodetection after electrophoresis, but this requires further evaluation. There is currently no satisfactory explanation for the lower immunodetection of MMP-2 in OD, as well as the absence of higher molecular weight complexes. The precise reason for the difference in the level of immunodetection between Western blotting and ELISA is unknown, but may be related to alteration of epitope recognition by modifications (e.g. glycosylation) or by interactions with denatured collagen or other non-collagenous proteins.

Greater amounts of immunodetection of pro- and mature MMP-2, as well as high molecular weight complexes, in the ID and MD may indicate recent synthesis of MMP-2 and MMP-2 complex formation with other non-collagenous proteins, such as chondroitin sulfate, which have been implicated in dentin mineralization [23, 27]. Additionally, some focus has been on a specific relationship between BSP and pro-/active MMP-2 with the suggestion that identification of these molecules in dentin may indicate involvement in dentinogenesis and dentin pathogenesis [25, 28]. For example it may be that during dentinogenesis proMMP-2 was activated by BSP without loss of the pro-domain and formed a complex with the dentin matrix collagen prior to mineralization $[25,28-29]$. Subsequent dentin mineralization and experimental demineralization may not have disrupted the BSP/pro-MMP-2 complex. These notions are subject to further investigation, however, as recent studies are not in support of the BSP activation of pro-MMP-2 or BSP/MMP-2 complex formation hypothesis [30]. The size and number of dentinal tubules (i.e. tubule content) in ID and MD may allow a greater source of matrix proteins (MMP-2 and other non-collagenous proteins) as compared with OD. Further assessment, with refined technologies, of the ratio of representative non-collagenous proteins in each region of dentin is clearly warranted.

Gelatinolytic activity associated with human coronal dentin has been reported to be primarily caused by endogenous MMPs [13]. Therefore, even though gelatin zymography will reveal activity from any type of gelatinase, this technique was used to compare the relative activity level of gelatinases with an apparent molecular weight consistent with pro- and mature MMP-2. Gelatinolytically active pro-MMP-2 and MMP-2 were detected in ID and MD whereas only MMP-2 was evident in the OD (Figure 4). The regional variation of gelatinolytic activity was similar to the detection of MMP-2 by Western blotting in that the activity was more readily visualized in the extract of MD. Early studies that envisioned that a MMP may be complexed with collagen and a TIMP, and the finding that TIMP-1 concentration increases as the pulp is approached may explain the finding that MMP-2 gelatinolytic activity was higher in MD than ID [5, 8, 31]. The presence of pro-MMP-2 in these regions may represent recent synthesis, and is in support of theories that consider dentin to be a bioactive matrix and dentinal tubules to provide the conduit for communication between dentin and the pulp [29, 32].

Initial experiments revealed that gelatinolytic activity in the ID and MD extracts was readily apparent when the lyophilized samples were dissolved directly in SDS sample buffer at $25{ }^{\circ} \mathrm{C}$. However, under these conditions, 
no gelatinolytic activity could be detected in the OD extract. Further pilot studies revealed that thermal denaturation of the dentin extracts at $60{ }^{\circ} \mathrm{C}$ for $1 \mathrm{~h}$ resulted in detection of gelatinolytic activity in the OD extract. Therefore, all dentin extracts were solubilized under these conditions. The requirement of OD thermal denaturation prior to detection of MMP-2 activity is suggestive of some type of protein/protein interaction that limits in vitro MMP-2 activity. Even under these conditions the significantly reduced gelatinolytic activity in the OD extract was not consistent with the results of ELISA. Gelatin zymography only reveals active proMMP-2 or MMP-2. Inactive forms or complexes resulting in MMP-2 inhibition may be present, but remain undetected using zymography. ELISA is able to detect active and inactive forms of proMMP-2 and MMP-2 as well as pro-MMP-2/TIMP and MMP-2/TIMP complexes. Therefore the apparent lower MMP-2 activity levels in ID and especially in OD may be partly explained by regional variations in MMP-2/collagen/TIMP complex formation. However, TIMP modification of apparent activity may not fully explain the low gelatinolytic activity observed in light of the observation, in the forming rat incisor, that the concentration of TIMP-1 and TIMP-2 may be lower in the region of the DEJ and mantle dentin as compared with other dentin regions closer to the pulp. Reduced activity in the OD may be a result of inhibition by proteins other than TIMPs or the changes made at the DEJ that precede initial mineralization may structurally alter MMP-2 and its relative activity. The inclusion of some enamel protein in the OD may result in MMP-2/protein interactions that potentially effect gelatinolytic activity after electrophoresis, but this notion requires further evaluation. It has been suggested that the DEJ is a highly specialized area with unique biological properties and complex protein interactions [33].

\section{Conclusion}

The concentration of MMP-2 based on ELISA is greatest in OD (which includes the DEJ), followed by ID and MD regions. However, levels of MMP-2 immunodetection (using Western blotting) and MMP-2 gelatinolytic activity (using gelatin zymography) do not correspond to the average concentration of MMP-2. The retained enzymatic activity after simultaneous demineralization and extraction with a chaotropic agent suggests remarkable stability of this enzyme and its potential role in dentin caries. Future studies should seek to identify if MMP-2 isolated from human dentin is able to digest collagen isolated from the same dentin and what mecha- nisms are involved in controlling its activity.

\section{References}

1 Linde A, Goldberg M. Dentinogenesis. Crit Rev Oral Biol Med 1993; 4: 679-728.

2 Fanchon S, Bourd K, Septier D, et al. Involvement of matrix metalloproteinases in the onset of dentin mineralization. Eur J Oral Sci 2004; 112: 171-176.

3 Satoyoshi M, Kawata A, Koizumui T, et al. Matrix metalloproteinase-2 in dentin matrix mineralization. J Endod 2001; 27: 462-466.

4 Fukae M, Tanabe T, Uchida T, et al. Enamelysin (matrix metalloproteinase-20): localization in the developing tooth and effects of $\mathrm{pH}$ and calcium on amelogenin hydrolysis. $J$ Dent Res 1998; 77: 1580-1588.

5 Goldberg M, Septier D, Bourd $\mathrm{K}$, et al. Immunohistochemical localization of MMP-2, MMP-9, TIMP-1, and TIMP-2 in the forming rat incisor. Connect Tissue Res 2003; 44: 143-153.

6 Boushell LW, Kaku M, Mochida Y, Bagnell R, Yamauchi M. Immunohistochemical localization of matrixmetalloproteinase-2 in human coronal dentin. Arch Oral Biol 2008; 53 : 109-116.

7 Palosaari $\mathrm{H}$, Wahlgren J, Larmas M, et al. The expression of MMP-8 in human odontoblasts and dental pulp cells is down-regulated by TGF-beta 1. J Dent Res 2000; 79: 77-84.

8 Ishiguro K, Yamashita K, Nakagaki K, Iwata K, Hayakawa T. Identification of tissue inhibitor of metalloproteinases-1 (TIMP-1) in human teeth and its distribution in cementum and dentine. Arch Oral Biol 1994; 39: 345-349.

9 Kawasaki K, Featherstone JD. Effects of collagenase on root demineralization. J Dent Res 1997; 76: 588-595.

10 Tjäderhane L, Larjava $\mathrm{H}$, Sorsa $\mathrm{T}$, et al. The activation and function of host matrix metalloproteinases in dentin matrix breakdown in caries lesions. J Dent Res 1998; 77: 16221629.

11 Hebling J, Pashley DH, Tjäderhane L, Tay FR. Chlorhexidine arrests subclinical degradation of dentin hybrid layers in vivo. J Dent Res 2005; 84: 741-746.

12 Mazzoni A, Mannello F, Tay FR, et al. Zymographic analysis and characterization of MMP-2 and -9 forms in human sound dentin. J Dent Res 2007; 86: 436-440.

13 Sulkala M, Tervahartiala T, Sorsa T, et al. Matrix metalloproteinase-8 (MMP-8) is the major collagenase in human dentin. Arch Oral Biol 2007; 52: 121-127.

14 Carrilho MRO, Carvalho RM, de Goes MF, et al. Chlorhexidine preserves dentin bond in vitro. $J$ Dent Res 2007; 86: 90-94.

15 Carrilho MR, Geraldeli S, Tay F, et al. In vivo preservation of the hybrid layer by chlorhexidine. $J$ Dent Res 2007; 86: $529-533$. 
16 Chaussain-Miller C, Fioretti F, Goldberg M, Menashi S. The role of matrix metalloproteinases (MMPs) in human caries. $J$ Dent Res 2006; 85: 22-32.

17 Santos J, Carrilho M, Tervahartiala T, et al. Determination of matrix metalloproteinases in human radicular dentin. $J$ Endod 2009; 35: 686-689.

18 Toledano M, Nieto-Aguilar R, Osorio R, et al. Differential expression of matrix metalloproteinase- 2 in human coronal and radicular sound and carious dentine. $J$ Dent 2010; 38: 635-640.

19 Clarkson BH, Hall DL, Heilman JR, Wefel JS. Effect of proteolytic enzymes on caries lesion formation in vitro. $J$ Oral Pathol 1986; 15: 423-429.

20 Dung SZ, Gregory RL, Li Y, Stookey GK. Effect of lactic acid and proteolytic enzymes on the release of organic matrix components from human root dentin. Caries Res 1995; 29: 483-489.

21 Termine JD, Belcourt AB, Conn KM, Kleinman HK. Mineral and collagen-binding proteins of fetal calf bone. $J$ Biol Chem 1981; 256: 10403-10408.

22 Stanton H, Fosang AJ. Matrix metalloproteinases are active following guanidine hydrochloride extraction of cartilage: generation of DIPEN neoepitope during dialysis. Matrix Biol 2002; 21: 425-428.

23 Waddington RJ, Hall RC, Embery G, Lloyd DM. Changing profiles of proteoglycans in the transition of predentin to dentin. Matrix Biol 2003; 22: 153-161.

24 Das S, Mandal M, Chakraborti T, Mandal A, Chakraborti S. Isolation of MMP-2 from MMP-2/TIMP-2 complex: characterization of the complex and the free enzyme in pulmonary vascular smooth muscle plasma membrane. Biochim Biophys
Acta 2004; 1674: 158-174.

25 Fedarko NS, Jain A, Karadag A, Fisher LW. Three small integrin-binding $\mathrm{N}$-linked glycoproteins (SIBLINGs) bind and activate specific matrix metalloproteinases. FASEB $J$ 2004; 18: 734-736.

26 Malla N, Sjøli S, Winberg J, Hadler-Olsen E, Uhlin-Hansen L. Biological and pathobiological functions of gelatinase dimers and complexes. Connect Tissue Res 2008; 49: 180184.

27 Steinfort J, van de Stadt R, Beertsen W. Identification of new rat dentin proteoglycans utilizing $\mathrm{C} 18$ chromatography. J Biol Chem 1994; 269: 22397-22404.

28 Huang B, Sun Y, Maciejewska I, et al. Distribution of SIBLING proteins in the organic and inorganic phases of rat dentin and bone. Eur J Oral Sci 2008; 116: 104-112.

29 Martin-De Las Heras S, Valenzuela A, Overall CM. The matrix metalloproteinase gelatinase $\mathrm{A}$ in human dentine. Arch Oral Biol 2000; 45: 757-765.

30 Hwang Q, Cheifetz S, Overall CM, et al. Bone sialoprotein does not interact with pro-gelatinase A (MMP-2) or mediate MMP-2 activation. BMC Cancer 2009; 9: 1-11.

31 Dayan D, Binderman I, Mechanic GL. A preliminary study of activation of collagenase in carious human dentin matrix. Arch Oral Biol 1983; 28: 185-187.

32 Baker SM, Sugars RV, Wendel M, et al. TGF- $\beta$ /extracellular matrix interactions in dentin matrix: a role in regulating sequestration and protection of bioactivity. Calcif Tissue Int 2009; 85: 66-74.

33 Goldberg M, Septier D, Bourd K, et al. The dentino-enamel junction revisited. Connect Tissue Res 2002; 43: 482-489. 